\title{
Quasi-objects, Cult Objects and Fashion Objects
}

On two Kinds of Fetishism on Display in Modern Culture

Andersen, Bjørn Schiermer

Published in:

Theory, Culture \& Society

DOI:

$10.1177 / 0263276410374632$

Publication date:

2011

Document version

Peer reviewed version

Citation for published version (APA):

Andersen, B. S. (2011). Quasi-objects, Cult Objects and Fashion Objects: On two Kinds of Fetishism on Display in Modern Culture. Theory, Culture \& Society, 28(1), 81-102. https://doi.org/10.1177/0263276410374632 


\title{
Quasi-objects, Cult Objects and Fashion Objects \\ On Two Kinds of Fetishism on Display in Modern Culture
}

\author{
Bjørn Schiermer
}

\begin{abstract}
This article attempts to rehabilitate the concept of fetishism and to contribute to the debate on the social role of objects as well as to fashion theory. Extrapolating from Michel Serres' theory of the quasi-objects, I distinguish two phenomenologies possessing almost opposite characteristics. These two phenomenologies are, so I argue, essential to quasi-object theory, yet largely ignored by Serres' sociological interpreters. They correspond with the two different theories of fetishism found in Marx and Durkheim, respectively. In the second half of the article, I introduce the fashion object as a unique opportunity for studying the interchange between these two forms of fetishism and their respective phenomenologies. Finally, returning to Serres, I briefly consider the theoretical consequences of introducing the fashion object as a quasi-object.
\end{abstract}

\section{Key words}

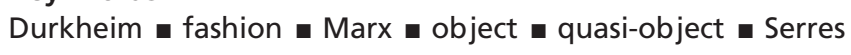

I HE FRENCH philosopher Michel Serres' concept of the quasi-object is the point of departure for this article, which is motivated by the the social fashion phenomena in the broadest sense of the word.

As we will see, appearances play an important part in Serres' account of the quasi-object. By reading Serres' actual descriptions of his

- Theory, Culture \& Society 2011 (SAGE, Los Angeles, London, New Delhi, and Singapore), Vol. 28(1): 81-102

DOI: 10.1177/0263276410374632 
quasi-objects, the article undertakes to distil two diverging phenomenologies at work in Serres. These two phenomenologies and their importance in relation to Serres' quasi-objects are largely ignored by the sociological theories that take up Serres' ideas. The article intends to show that the two phenomenologies at stake in Serres correspond to two paradigmatic theories of fetishism, namely the Marxist and the Durkheimian one, respectively. Consequently, instead of consulting Serres' sociological heirs, I try to unfold insights from the two sociological classics within a quasi-object theoretical framework.

In the second part of the article, I try to show how these two ideas of fetishism might blend and interact; and how, notably, they may contribute to explain the functioning of an important genre of quasi-objects: fashion objects. In conclusion, I briefly sketch the theoretical consequences of my discovery of this new quasi-object for quasi-object theory.

With regard to fetishism, it is in the first instance the peculiar phenomenology of the fetishized object that interests me. The concept of phenomenology used in this article refers loosely to the phenomenological philosophical tradition. What is important to me is not the analysis of constituting 'mental acts', or of 'existential' structures regarding 'being in the world' as such, but to take what is experienced in the 'natural attitude' or in the 'mode of everydayness' in face of fetishized objects seriously and to find adequate conceptual tools to unfold these experiences. I hope to show that this can be done on the basis of Durkheimian and Marxist theories of fetishism. ${ }^{1}$ Thus my concept of phenomenology has two aspects: it presents an epistemological approach, 'going to the things themselves' (as they are experienced), as well as an emphasis on the fact that appearances of objects matter. The latter dimension is important when speaking about fetishized objects, since their particular appearances are decisive to their social functioning.

In my view - and undoubtedly to a certain degree in spite of Serres himself - the strength of Serres' quasi-object theory is that it makes such a phenomenological approach to fetishism possible and, consequently, makes it possible to add a phenomenological dimension to quasi-object theory. First of all, however, an outline of Serres' own efforts.

\section{'Le quasi-objet'}

Emerging for the first time in Serres' book The Parasite (1982a), the notion of the quasi-object is intimately connected to Serres' understanding of the social as parasitic relations between individuals and to Réné Girard's conception of exclusion and sacrifice. What interests me in this article, however, is primarily the fetishist relation between the social and the material, to which Serres' concept of the quasi-object, in my view, constitutes a unique possibility of access and, to a lesser degree, his illustrations of how the quasi-object function as a constituting 'marker' of individuality. 
Paramount to the idea of the quasi-object is the thought that its ontology cannot be separated from its social function: "the object is a quasiobject in as much as it remains a quasi-we. It is more a contract than a thing', Serres writes in Genèse (1982b: 147). ${ }^{2}$ As his first examples in The Parasite show, its social circulation co-constitutes both the object and the subject:

This quasi-object is not an object, but it is one nevertheless, since it is not a subject, since it is in the world; it is also a quasi-subject, since it marks or designates a subject who, without it, would not be a subject. (1982a: 225)

Serres uses the example of a ball game. On the one hand, there would be no social gathering without the ball. The ball game is held together by an object. On the other hand, an unused ball is 'nothing. It only serves its purposes while the game is ongoing. Thus, from the ball's perspective, everything arranges itself around it. It selects its players and determines their actions: 'The ball isn't there for the body; the exact contrary is true: the body is the object of the ball, the subject moves around the sun', Serres asserts (1982a: 226). There is no ball without the players, but then again no players without the ball.

Sociality, Serres illustrates, is held together by the circulation of objects. Objects help to structure the specific situations of our social life. No social interaction takes place without material or immaterial objects (pronouns being the archetypical quasi-objects; see Serres and Latour, 1995: 200-2). Accordingly, one should avoid hypostasizing the social sui generis, just as one should avoid objectifying the object as some kind of isolated and mute materiality. In short, one should seek to portray the cultural and social praxis as going on between these extremes.

Objects incorporate and maintain interactional patterns over time. They remain identical, which is why they transcend the specific situation and bind different contexts together. In Genèse (1982b), Serres takes as his starting point a society of simians functioning without objects. Ape society is to be understood as a society of absolute co-presence; a society wholly without structure and building on the immediate interdependency of all its members. Consequently, it has to be constantly 'enacted' in the presence of everyone and remains on a purely interactional level. As is well known, Bruno Latour (together with Michael Callon and John Law) has further developed this line of thinking under the heading of Actor-Network Theory (ANT). Latour understands structure as an interlacing of 'actions' of specific artefacts; as a constant 'globalization' and 'localization' of a situation or a 'site' in an 'actor-network' which relates it to other sites by way of the interchange of objects. Thus, compared to ape society, human sociality is 'dislocated'. It exists having neither 'simultaneity nor continuity nor homogeneity' (Latour, 1996: 234) - and all of this due to the use of objects.

However, probably because of its origin in so-called Science and Technology Studies (STS), ANT emphasizes the practical or technical use 
of artefacts and remains particularly fascinated by the scientific institution and the scientific object. A critique of the 'technicist' bias of ANT cannot be unfolded here. Yet the fundamental idea of this article is the fact that there is more to the object than its instrumental function or its specific practical embeddedness; this being first and foremost the question of appearance and of fetishist dynamics. According to Latour the concept of fetishism denies the autonomy of the object by ascribing its 'actions' to humans or to hidden social forces. Thus, because of his aversion to the notion of fetishism, Latour neglects the aspects of fetishism which are present de facto in Serres. ${ }^{3}$

\section{Fetishism and Appearance in Serres}

It is time to approach the main theme of this article, namely the question of fetishes and fetishist phenomenologies; of affectionate relations and identifications, of peculiar and strong appearances, and of specular and sensuous dealings with the object world.

In Genèse (1982b), Serres' discourse on the quasi-object is of immediate sociological relevance: it becomes clear that religion, the military and economics (and science) correspond to certain quasi-objects of particular societal importance. There would be no religion without holy objects; no exchange without money and commodities; and no war (or terror balance) without weapons (1982b: 150ff.). According to Serres, these are the crucial quasi-objects on an institutional level.

Now, for our purposes, it is important to notice how Serres, in his actual descriptions of the institutionalized quasi-objects, attributes exceptional phenomenological qualities to them. Although he primarily uses the fetish concept in a rather narrow sense - namely to designate the religious type of quasi-object (1982b: 150) - it is obvious that in Serres all important quasi-objects are to a certain degree fetishes. For example, in Serres' critical diagnosis of culture, scientific objects are becoming ever more fetishized. Science may replace 'the society of priests', Serres states (1982b: 151). One may think about the fascinating technical gadget as a replacement for the religious relic.

However, if all the quasi-objects are at least partly fetishes, they are so - and this is of paramount importance to this article - not because they are institutionalized on behalf of an established religion in the narrow sense, but simply because they are tangible focal points for social attention, and it is to this social investment or significance that they owe their extraordinary appearances. In The Parasite, the quasi-object is described on the general level, as we saw, as a 'sun' (1982a: 226); and in Genèse, Serres uses such words as 'spectacle', 'luminous', 'veneration', 'terror' and 'lightning' (1982b: 146ff.). Because of their extraordinary appearance, such objects discard language in favour of a 'mute contract' (1982b: 150). ${ }^{4}$ To function as quasi-objects, i.e. to structure the social context, it is enough for them here, Serres is thinking about nuclear weapons - to be 'shown' or 'presented'; 
to be seen, felt or heard (1982b: 147). When Serres finally tells us that the function of the quasi-object is to 'objectify the social bond' [le lien social] (1982b: 147), this wording indeed sounds Marxist or Durkheimian.

If we look at Serres' caricature of the philosophical conception of the scientific object, it becomes even clearer that the remarkable phenomenological attributes of the quasi-object do not appertain to the object itself, but stem from the sociality which is 'objectified', incorporated or incarnated in the object:

What is an object of science? It is simply, purely an object. An object outside the field of relations, not a quasi-object, not a pre-object [...]. One could even guess where this so-called objective cognition comes from. From a thing of no interest [D'une chose sans intérêt] that is allowed to provoke neither desire nor passion. (1982b: 150)

In the conventional conception of the psychological side of the constitution of the scientific object, it is precisely its phenomenological neutrality and objectivity that distinguishes the scientific object. 'Cold scientific distance' turns the scientific object into a 'pure object'; an objectified object one might say; an object with which we have no interaction. Conversely, it is precisely the projection of sentiment onto the object, the 'desire' for it or the 'passionate' relation with it, which characterizes a quasi-object (1982b: 150). Of course, the scientific object in real 'laboratory life' is also a quasi-object. In reality, the 'pure' object of philosophy is a very 'impure' object, condensing a multitude of affections, projections and social relations.

Another interesting case is Serres' description of money. In its structuring role, money is the most powerful and general quasi-object in existence. It might even replace or direct, charge or prepare the way for other quasi-objects, substituting itself for religious relics or weapons. The chief characteristic of money, and the reason why it might substitute for other objects, is its symbolic generality: 'These quasi-objects are blank, and the subjects are transparent', Serres writes (1982a: 230). No one is excluded. Money does not discriminate, which is exactly why those who have none are discriminated against. Like no other quasi-object, money can polarize, 'asymmetrize' and sequence the social in parasitic chains (1982b: 152ff.). But money is also a 'blank' object or a 'joker' in another sense. Serres makes direct reference to Marx's conception of money as 'a general equivalent' (1982a: 229). Money transforms all qualitative differences into quantitative ones, it transforms matter into air. It has only a little materiality left in itself. Hollowed out from within, it is transformed into a sheer symbol of value.

One should notice that the description of money strikingly contrasts with the energetic overall description of the quasi-object. Whereas other quasi-objects seem less transparent and dull - 'Interest increases with opacity and blackness', Serres writes (1982a: 230) - money is described as 
bland and trivial in its appearance. In contrast with the other quasi-objects, the social investment in money, it seems, does not lend to it a special phenomenology after all. In spite of its ability to structure social life at large, money looks strangely inconspicuous. It structures social life precisely through its ability to hide its enormous powers.

Thus there are, in fact, two different or even opposed phenomenologies at work in Serres' actual descriptions: an inconspicuous or trivial one and an energetic and conspicuous one. To really understand these two phenomenologies in direct connection with the different forms of fetishism that cause them, we have to sketch the social and societal mechanisms behind them. To fulfil this purpose, it is my conviction that we need to revisit Durkheim and Marx and their respective accounts of fetishism. As already hinted at in the beginning of the article, even if this might seem a familiar path, we are in for some surprises.

\section{Durkheim and the Cult Object}

Durkheim is not known for 'socializing' objects. Rather, he is known for the opposite: for objectifying the social, that is. What is more, according to Durkheim's methodological programme, this objectification is to take place against the background of a positivist scientific ontology, which in no way does justice to our practical and phenomenological dealings with objects. Fortunately, the late Durkheim's own scientific endeavours do not live up to his methodological proclamations. In a word, Durkheim's sociology of religion is not simply about social things but also about social things; about sacred objects. Thus, in Durkheim, the sacred object (the representation or the symbol of the totem) is placed overtly at the centre of religious attention; it is the object of a conscious cult and of shared veneration and fear. Durkheim 'socializes' objects, albeit not in relation to their function, their inherent technical possibilities, their usefulness or their character as tools, but in relation to their appearance. The totem attracts the gaze; it captures attention and embodies energetic charges. It is through its extraordinary phenomenology that the object of the cult functions as a quasi-object.

We should not let ourselves be disturbed by Durkheim's dislike of the term 'fetish'. It derives from his reading of James Frazer (and others), who uses the concept in a rather individualistic way and ignores the social origin of the fetish object. ${ }^{5}$ When I speak of Durkheimian fetishism or of the cult object in the following, I take it to be in agreement with Durkheim's own conception: insisting on the existence of collective powers 'projected onto the objects' [projetée dans les choses] (1998: 519).

My interpretation of Durkheim takes its point of departure in his concept of 'exteriorization':

Without doubt, since collective sentiments cannot become aware of themselves without attaching to objects, [religious forces] could not have constituted themselves if they had not taken from objects some of their 
characteristics: in this way they have acquired a kind of psychical nature, and, in this capacity, they have begun to intermingle with life in the material world [...] (1998: 214)

Without the object there is no cult in the proper sense of the word, and without the cult there is no object. Collective sentiments can only become 'aware of themselves', Durkheim ascertains, by turning away from themselves; by taking on visual and 'material' shapes; by cultural sublimation, so to speak (see also Durkheim, 1998: 512ff.). Thus, on the one hand, social forces have to attach themselves to the object; on the other, the object diverts attention from the social relation. The social or 'moral' forces are represented as something else by mythical imagination - as gods or god-like creatures or powers.

In the cultic ritual, exteriorization is intensified. The social as such is never consciously celebrated: the participants in the ritual do not know that they are in fact worshipping the social - even though, of course, they do feel it. People congregate to worship something external to the cult and to carry out rituals upholding the universe. When the soldier kisses the flag or the sailor chooses to sport a tattoo, he performs or enacts a mimetic ritual and thereby feels part of the group, but he does not carry out the ritual with this purpose in mind.

Thus, in a certain sense, the cult turns signs into objects. True, the sacred symbol designates definite mythical powers or figures - and these representations can then, theoretically, be led back to particular social or societal structures by the Durkheimian sociologist. And yet, what is essential to the object is not its symbolic or cultural meaning, but its specific religious function. This is because the social energies incorporate themselves into the symbol-sign or the emblem, charging the physical appearance and the material properties of it, in order that it may gather the devotees around itself. Moreover, these energies are 'contagious'. They rub off, not only on the objects near or related to the sacred object, but also on representations of it, and thus turn the emblem into a sacred object in itself. Thus it is the emblem which is the specific target of the cult, Durkheim states, not the totem animal as such (1998: 244). Finally, the sacred status of the object is due to the powers emanating from it, whereas its cultural or mythical significance is a later rationalization of these blind energies.

These energies create energetic phenomenologies. Once invested in the object, they turn back on the individuals in the form of 'veritable forces', 'even, in a sense, [as] material forces that cause physical effects'. In fact, if the individual enters into contact with these forces without precaution, he 'receives a shock comparable to that stemming from an electric discharge' (1998: 270-1). This is exteriorization driven to its extreme. The social origin of the cult is transformed into a radiance or shine, a force that seems to emanate from the object itself, and this is the reason why it is respected, celebrated, looked upon with fear and awe, and surrounded by 
taboos and rituals. The sign inflates. It does not stop signifying, but what is truly important is not what it 'says', but what it does.

These thoughts correspond to Durkheim's more general reflections. Again: the symbolic, the birth of (religious) culture, of myth, is described as an alienation of the social from itself:

The distance between society as it is objectively and the holy objects that represent it symbolically is considerable. It was necessary that the impressions really felt by man - the impressions serving as original material for this [symbolical, BS] construction - were interpreted, elaborated, transformed until they were no longer recognizable. The world of religious objects is thus, but only in its outer form, a world that is partly imaginary. It is exactly for these reasons that it lends itself to the free creativity of the mind. (1998: 544-5)

'The impressions really felt by man' are irrevocably lost. Yet one can imagine the blind, immediate and senseless form of the social cult before the $\operatorname{arch}$-fissure due to the insertion of the cultic object took place. Without an object to attach to, the cult cannot direct the engendered energies outwards. No sublimation takes place. No detour around sacred emblems. No projections and no fetishism. If this closed-off, senseless experience of the purely social is placed at one end of a continuum, autonomous culture 'free creativity of the mind' - constitutes the other extreme. In modern institutionalized art or science the cult is (nearly) imperceptible - even though it may prosper in more narrow avant-garde, bohemian or practical scientific contexts. Thus, historically, the symbolic order is to an ever increasing extent characterized by structuring principles other than the original social ones.

Evidently, this rupture is in no way ultimate. True, in 'primitive' religions the distance between the social and the symbolical is shorter than in developed religious cultures inasmuch as the totem of the clan directly 'symbolizes' the clan itself, yet there is no qualitative difference between archaic and modern cults. Modern society is not bereft of collective ritual and cultic objects. As Durkheim's comments on science and public opinion show, he is perfectly aware of the influence of what we could call quasireligious forces in modern society - and their presence in secular areas where we are unaware of them, or where we do not expect to find them (1998: 298, 625-6). Most institutions within modern differentiated culture are susceptible to influence from the cult.

On the other hand, in the established or institutionalized churches, the strong energies are, Durkheim finds, largely dried out (1998: 10, 34, 610). As Serres remarked, the religious fetishes are dead. Likewise, Durkheim finds that religion, in the sense we normally understand the word, might disappear. Yet the cult, Durkheim insists, will persevere (1998: 615). Indeed, as we will see, the conspicuous phenomenology that Durkheim describes is also to be found in modern culture. First, however, we have to 
address the other and inconspicuous phenomenology we found in Serres' descriptions of money. This phenomenology I intend to retrieve in Marx.

\section{Marx and Trivial Commodities}

The concept of fetishism in Marxist literature has been extensively discussed. Probably some of the passages in the fourth part of the first chapter of Das Kapital about 'the fetish character of the commodity and the secret thereof' are among the most cited in the history of sociology (1973: 85ff.). However, to really understand Marx's way of using the fetish concept, it is worthwhile to make a detour around the young Marx.

It is well known that the young Marx, precisely like Serres (and Latour), differentiates man from animals by man's capability to produce objects (see for instance Marx, 1971: 357). Moreover, as is clear from Marx's Thesen über Feuerbach (1971), this concept of production is understood as 'work' in a very broad sense: as praxis, as an active bodily and sensuous interaction with artefacts. Fully in line with quasi-object thinking albeit in a more humanistic vocabulary - Marx describes the mediation between humans and the world of objects as a simultaneous and reciprocal construction going on between the poles of detached subjectivity and selfsufficient objects. ${ }^{6}$ However, this 'ontological symmetry' between man and object is destroyed under capitalism. Here, Marx asserts, work is reduced to alienating wage labour, and artefacts are only accessible as commodities. Because of the private ownership of the means of production, the organization of production and the circulation of objects are left to anonymous market processes surpassing individual cognition. The notion of obscure supra-individual dynamics also plays a crucial role in the mature Marx. In Das Kapital, Marx describes hidden or obscure antagonistic 'laws of motion' (of value) surfacing in the dynamics and the accumulation of capital. These dynamics pertain to the system as a whole and thus go on 'behind the back' of the individual.

Even though the mature Marx's focus is allegedly more 'objectivist' or 'scientific', the phenomenological consequences of this hidden but all-encompassing dynamic is crucial to Marx's notion of fetishism. Instead of expressing itself rationally in the conscious planning of the societal production (communism), the interplay of human sociality is transferred to the market or transformed in obscure circulations and distributions of value; disseminated through irrational, contradictory and autonomous dynamics out of reach of human control. This goes of course for the purchase or the sale of labour (or 'labour power'), too. Work is commodified and generalized. Since commodification of work demands an abstraction from all the qualitatively different ways of working, our interaction with the object world congeals into hard quantitative and objective measures as abstract human work'. In this way, what really creates value is obscured behind the dynamics of the market in favour of an abstract notion of labour, which apparently makes things 'worth something', furnishes them with an inherent but 
abstract (pecuniary) value. In the phenomenology of what Marx calls 'everyday fetishism' or 'religion of everyday life' (1964: 684), naturalized by 'the vulgar economists', we even experience the value of the commodity as emanating from within.

Yet, and this is important to us, this experience remains strangely impoverished and intangible. Commodities, Marx writes, are 'sensuous' in their 'non-sensuousness' or supra-sensuousness (1973: 85). They are real objects, but at the same time abstract constructions. On the one hand, if one attempts to study the commodity up close, its commodity value (exchange value) slips through one's fingers: 'One may [...] twist and turn a particular commodity how one will; it remains incomprehensible as a thing of value', Marx writes (1973: 62). On the other hand, even if one may prove scientifically that value is not a natural property of the thing, still one cannot escape the fiction that it is. Even Marx's own scientific achievements are impotent in the face of everyday fetishism. To the person 'trapped in the conditions of capitalist production', the phenomenology of commodity value 'seems' [erscheint] 'just as final' after Marx's discovery as before much in the same way, Marx goes on, as 'the scientific decomposition of air into its elements' does not interfere with the experience of air as a 'physical form of volume' (1973: 88). The phenomenology of fetishism cannot be transcended from within. One may even read Marx and therefore know that the commodity and its value is a social construction, and still, one has no access to a post-capitalistic experience. Indeed, the Marxist scientist has to go to the market to buy groceries, too.

It is, however, not terribly exciting to buy one's groceries. Rather the opposite is true:

At first sight, a commodity seems to be a self-evident [selbstverständliches], trivial thing. The analysis of it shows that it is a really intricate thing loaded with metaphysical quibbles and theological whims. (1973: 85)

The task of Marx's critique of commodity fetishism is not to explain away as 'fetishist' what makes an object magic or fantastic; rather, it is to explain as magic or fantastic the appearance of the ordinary and trivial. Instead of attributing powers to things that they do not really possess, the Marxist account describes how things possess powers that do not show. Marxist fetishism naturalizes. It makes real what is surreal, and natural what is supra-natural - and not the other way around.

If Marx with his critical explanation [Darstellung] were able to show us what we 'are really doing [...] without knowing it' (1973: 88), it would not be a pleasant experience. Behind the misty veil of fetishism, things 'count' as nothing but 'objectified vessels' [sachliche Hüllen] (1973: 88); they are 'solidified crystallizations' [bloße Gallerte] (1973: 52) of abstract work; they are ghostly 'objectifications' [gespenstige Gegenständlichkeit] (1973: 52); or they are turned into 'social hieroglyphs' that nobody knows how to read (1973: 88). While people think they perceive trivial material 
objects, the hollow soul of the commodity asserts itself, quantifying all qualitative differences, abstracting from the corporeal nature of the objects and extinguishing their sensuous qualities (1973: 51ff.). Thus capitalism, Marx states, is a nightmare. Fetishism ensures that it is rarely or only obscurely experienced as such, but fetishism in no way makes it a pleasant dream. Rather, the fetishist dream is one of those dreams that one does not remember at all.

Taking a step back, one cannot help but wonder. After all, talking about fetishes, one should expect the opposite dialectic: not things that seem ordinary, yet are laden with power and metaphysics, but things that seem powerful and metaphysical, yet in fact are ordinary. One would expect the fetishist experience to be a spectacle of animistic enchantment. Indeed in this light, Marx's well-known 'analogy to the obscure regions of the religious world' (1973: 86) is somehow misleading. We are far away from the powerful and expressive fetishism of natural religions. On the contrary, Marx's fetish has proven explicitly non-sensuous or non-aesthetic. In fact, in his account of the commodity fetish there are lots of appearances but no shine. The fetishism of the commodity is indeed a secret.

Yet why then does Marx on numerous occasions in Das Kapital use the German adjective 'blendend, in the sense of 'dazzling', 'glaring' or 'blinding"? He even speaks of the "eye-blinding enigma of the commodity fetish' (1973: 108). These characteristics, apparently appertaining to the commodity world as such, are not at all set in relation to Marx's phenomenological characterization of the fetish developed in the 'official' section on commodity fetishism, although they glaringly contrast with the trivial appearance described there. In Serres, we found the same ambivalence. On the one hand, we saw that the function of money depended upon its utter anonymity. Money consists of absolutely 'blank' objects. Yet, on the other hand, precisely as in Marx, Serres' quasi-objects also seem to serve as focal points for specific social projections. Indeed, they are described as fetishes evoking fear and wonder.

We cannot find the origin of this energetic phenomenology in Marx. As a matter of fact we have already found it in Durkheim. To keep them apart analytically, I should like to distil the differences between the two phenomenologies.

\section{Conspicuous and Inconspicuous Fetishism}

In Marx, the fetishized object hides its magical or quasi-religious character behind a semblance of normality. In Durkheim, it hides its normality behind a semblance of magic and an evocation of religious sensation. In the former case, the condition for the propagation of objects is a kind of attraction which has no real sensuous merit. Behind the abstract sensation of value, anonymous and autonomous forces hide that are on display in the circuit of things around us, standardizing, levelling and homogenizing culture at large. In Durkheim, by contrast, objects owe their popular attraction 
to their extraordinary, singular and sensuous appearance. In Marx there is no outright social projection; rather, his concept of fetishism attempts to trace the phenomenological consequences of the existence of functional dynamics and laws, impenetrable to the individual, yet somehow surfacing in his or her actions, leaving him or her with the obscure sensation (if any at all) of being subject to social forces that undermine his or her individual autonomy and erode the particularity and materiality of the objects around him or her. If Durkheim, to use the language of George Ritzer (2005: 118ff.), analyses how to make 'something' out of 'nothing', Marx rather attempts to show how, underneath this 'something', there is in fact 'nothing' - nothing, that is, but an abstract notion of 'equivalence. There is nothing conspicuous about Marx's commodities. Rather it is their inconspicuousness that is conspicuous. The opposite is true of the cult object: its conspicuousness is inconspicuous.

In Marx as well as in Serres, we missed a clear distinction between these two phenomenologies and their respective sources. The same confusion is on display in a lot of Marxist-inspired sociology of consumption or of 'commodity culture'. Considering, for instance, accounts like Guy Debord's Société du spectacle (1992) or Wolfgang Fritz Haug's Kritik der Warenästhetik (1976), it is obvious that they both seek to come to grips with a phenomenology that is at one and the same time abundant and shallow; prodigal as well as poor. In Debord, the 'spectacle' is depicted simply as 'privation becoming richer' (1992: §44); while for Haug, 'destitution [Armut] shows itself as abundance' in capitalism (1976: 119). Both Haug and Debord describe how the commodity takes on a conspicuous phenomenology that hides its inner shallowness. Debord even speaks of a 'cunning of the commodity reason' by which the 'commodity form' displays a varnish of sensuousness and particularity, while at the same time "moving towards its most complete realization' (1992: §61). Haug speaks of a 'technocracy of the human senses' that 'controls humans by way of their fascination' (1976: 55).

In these two accounts we are clearly dealing with phenomenologies that cannot be theoretically accounted for on the basis of Marx's 'official' account of fetishism alone - and that clearly reveal a Durkheimian trait. It is Durkheimian fetishism which disguises the abstract erosion brought about by the commodity form. And yet, probably because they remain too attached to a Marxist framework, both authors avoid addressing the Durkheimian surplus. Consequently, as is common in the 'critical tradition', they inflate Marx's fetish to a point where it assumes the contours of a cult object, unaware that this is not in line with Marx's explicit concept.

This is a fatal misconception. It is a mistake to reduce the strong cultic phenomenology to a means invented and controlled by capitalism for the purpose of deliberate manipulation. In this way, academic embarrassment concerning the ontology of the cult object is disguised as critique. Thus, it is not capitalism that controls or creates the cult and the lustre it confers to its objects. ${ }^{7}$ In fact, it may even be the other way around. 
True, the fascinations of the cult, as well as its possible formations and dispersions, are often deeply influenced by inventive aestheticization and manipulative advertising; yet the different forms of embellishment, illumination, eroticization and theatricalization in the warehouse or in advertising are themselves subject to particular cultic fascinations and identifications. They are, as we will see, subject to fashion dynamics. Moreover, the allure of the cult objects has nothing to do with any aesthetic shine. It cannot be 'manufactured' from above - or in any haute couture atelier - but has to be engendered by the cult. Here we are dealing with an 'emergent' process with a proper or inherent logic: cult objects are subject to common affection because they shine, and they shine because they are subject to common affection. Moreover, cult objects abound outside the reach of economical interest.

Thus we need to keep separate things apart. This is also the point of the young Jean Baudrillard. In his Pour une critique de l'économie politique du signe (2007), Baudrillard insists on the profound difference between our two kinds of fetishism. Baudrillard not only saw the need to break up the narrow and increasingly anachronistic Marxist production paradigm; he also insisted on the inconspicuous or naturalizing phenomenology of Marxist fetishism. In fact, he defines the concept of fetishism in direct opposition to a (pre-structuralist) anthropological or ethnological conception akin to the Durkheimian one described above (2007: 99-103). Thus, to Baudrillard, "fetishism is not the sacralization of this or that object [...], but a "fetishism of the system as such" (2007: 101). Consequently, Baudrillard is also loyal to the phenomenological characteristics of Marx's original concept. We are dealing with a privative fetishism. It is all about concealing from the individual his or her 'captivation in the coercive logic of a system of abstraction' (2007: 101), about hiding the despotic arbitrariness, the logic and the function of the self-contained differential system of needs, of desires, of status and of distinction. ${ }^{8}$

So much about inconspicuous fetishism for now. Before I show how the two forms of fetishism work together in the fashion object, we have to make some changes to the Durkheimian account.

\section{Expanding Durkheim}

Fundamentally, I should like to enlarge and decentralize the Durkheimian cult. Thus we need to elaborate a bit on Durkheim's notions. Speaking about the 'representations' of the totems, Durkheim tells us that:

they reach their maximum of intensity at the moment where the individuals are assembled in an unmediated rapport with one another, where they all partake of the same idea or the same feeling [sentiment]. But once the assembly is dissolved and each and every one has resumed their proper existence they [the representations, BS] gradually lose their energy. (1998: 493) 
Without recurrent ritual charging and recharging of the cult object, it loses its energetic appearance. And yet the Durkheimian cult object escapes or 'survives' the narrow ritual. It holds the clan together in the periods between the cultic gatherings. In this way the cult object actually breaks up the sharp barrier erected by Durkheim between the sacred and profane, between ritual and everyday life. These considerations are mirrored at a more general level:

The violent passions which are stirred up in the midst of a crowd diminish and blur once the crowd dissolves, and the individuals ask themselves with consternation how they have become carried away to this extent from their true being. But if the movements by which these sentiments expressed themselves are inscribed on objects that endure, they become, themselves, durable. These objects constantly remind consciousness of these sentiments and keep them permanently awake. (1998: 330)

The object slows down, deflects, and extends the imitational movements of the crowd. By investing its powers in an object, the 'hot' mob, the crowd or the cult can be enlarged, or even dispersed, without completely losing its influence: the object makes it possible for the social to extend its powers into individualized existence. Thus, as we will see, the experience that Durkheim mentions of being 'carried away' or of losing oneself is precisely not restricted to crowd hysteria. The social does not stop with the crowd. Once charged, the cult object continues to shine (for a while) even when the individual is alone; which makes it hard, or even impossible, to distinguish individual from collective object fascinations and identifications.

These extrapolations explain how it is possible for the cult to exist without being self-conscious, so to speak. In other words, it makes it possible that one might even be a member of a cult or a clan without knowing it. No symbol is needed. The object simply holds the clan together solely through its extraordinary appearance.

Thus I should like, finally, to secularize the Durkheimian clan, not dispersing it or breaking it up totally, but 'disembedding' it; to make it dependent on modern mass media and communications tools and thus to enlarge its circumference a great deal. From this point of view, we may conceive of clans and cults that are less self-aware, less personal; and cults that are much less intensive. We may think of a multiplicity of clans entangled with one another; some longer-lasting, some perishing as suddenly as they emerge; some more intimate and closed, and some vast and heterogenic and all this made possible by the cultic object.

It is time to concretize our reflections a bit. How might our two forms of fetishism work together? How do their phenomenologies blend? To answer these questions, I introduce the fashion object. In the following, I shall describe how it unites Durkheimian and Marxist viewpoints. 


\section{The Fashion Object - The Conspicuous Side}

It is obvious that the objects with which we are dealing belong to a class of quasi-objects which work rather differently than the ones found in ANT or STS. We might think of the glamour of royals and celebrities; about famous artworks; about staged mass events and the fascination that emanates from certain political, national or religious symbols; about dress and apparel; about names, ways of verbal expression, gestures and dialects; or even about certain 'sexy' ideologies or currents of a political, religious, aesthetic or scientific nature. All these objects are cult objects.

The fashion object is primarily a temporalized and individualized cult object. In contrast to the cult object, fashion objects make room for individuality, for individual interpretation and Goffmanian front stage work. Thus, in the case of the genuine cult object, the group is aware of itself as group. It knows, at least implicitly, that the cult object is a symbol of its collective identity. The fashion object, by contrast, is not perceived as a cult object, since it binds the clan exclusively by its extraordinary phenomenological attractions. It rather presents an immediate possibility for self-expression and is, consequently, abandoned when its social origin is recognized. The cult is then dissolved. Genuine cult objects - national flags, political or religious symbols, totems, kings, legal constitutions and human rights concepts, certain places, buildings and museums, the notion of 'man' or the individual (Durkheim's modern cult object), and maybe certain 'classic' artworks - are not subject to temporal dynamics. Temporality had no place in Durkheimian thought on primitive religion. The genuine cult-object, we saw, persists - and so does the Durkheimian clan.

The borders between the genuine cult object and its modern and temporalized relative is blurred and subject to negotiation and conflict. At times, one may witness deliberate attempts to turn fashion objects into genuine cult objects for political or patriotic (military) reasons, just as economic interest might try to turn cult objects into fashion objects. Again, however, one should not overestimate the actual success of such attempts. It would be more correct to stay in the phenomenological register and simply remark that fashion objects, just like cult objects, are 'contagious': they rub off on neighbouring or related objects, 'infecting' them with their shine - most importantly, of course, on their bearer or their utterer. Sometimes certain celebrities or personalities are themselves turned into fashion or cult objects - famousness engenders famousness - in which case everything they touch may start to shine. Such persons may have it in their power to instigate a fashion or cult object, and yet this power is itself invested in them by yet another cult.

The habitual Serres reader might not involuntarily associate Serres' seemingly abstract expression that objects 'slow down the time of our revolutions' (1982b: 146) with fashion. Yet maybe they should. On the one hand, the fashion object displays archaic traits. It originates from the cultic ritual which it makes possible by throwing the social energies that it receives 
back at the group. On the other hand, the fashion object is genuinely modern. Not only does it slow down the 'immaterial' mimesis of the 'herd' by a detour over objects; not only does it cool down the unorganized crowd of mass psychology by breaking up co-presence and immediacy; it also creates room for individual 'interpellation' and modern forms of subjectivation - and it does so in a much more intensive and dangerous way than other quasi-objects. It creates a scene for individualization which it constantly undermines. It thus secures a temporary stability in the constant transformations of the material or immaterial surroundings of modernity - a dynamic stabilization needed when religion and tradition lose their tight grip on social and individual identities (see Esposito, 2004). Many loose and plural modern identities; many clans, groups or 'neo-tribes'; and many social contexts in modern social life are held together only by the fragile laces of fashion objects.

Thus, fashion binds temporality, individuality, sociality and materiality in the fashion object. The following quote, stemming from an anonymous American woman returning from abroad in 1947, appositely illustrates this multiple dialectic:

At every airport where we stopped on the way back from China I started watching the women coming the other way. At Calcutta the first long skirt and unpadded shoulders looked like something out of a masquerade party. At the American installations in Frankfurt (also in Vienna), a lot of the newer arrivals were converted and were catching everyone's attention. At the airport in Shannon I had a long wait; I got into a conversation with a lady en route to Europe. She was from San Francisco and told me that there they hadn't been completely won over; just as many were wearing the long skirts as not. But as she flew east, she found that just about everybody in New York had gone in for the new style. [...] By the time I took the train from New York for home, my short skirts felt conspicuous and my shoulders seemed awfully wide! ${ }^{9}$

Does this woman know she is participating in a cult? Evidently she is vaguely aware of some kind of connection between the interactional level and the fact that a sacred object is constituted before her eyes. And yet she might reflect as much as she likes, she cannot prevent the new and shining object from coming to the fore - nor, conversely, can she prevent herself from disliking the objects soon to be abandoned. The attraction of the object diverts her consciousness from the fact that she participates in rituals which hold together an even vaster and less organized and centred group: a clan.

The clan is, according to Durkheim, dependent on narrower rituals; dependent on the cult, that is. Thus, fashion phenomena might suddenly emerge out of myriad small and implicit rituals centred upon objects; as Serres would put it, out of 'noise' or 'black multiplicity'. As employed here, the concept of cultic ritual includes the casual encounter in the street or in 
the airport; the talk about a certain philosopher or a scientific theory gaining popularity; or the subcultural veneration of certain objects; it includes collective window-shopping or common consumption of all kinds; the important thing is that shared sentiments and affections are provoked and cultic objects constituted. It does not make sense to ask what came first, object or cult. To the extent that Durkheimian effervescence is engendered, it emanates from the object and vice versa.

Thus, like cult objects, fashion objects are subject to rituals, albeit of a more implicit and transparent kind. These rituals are not negotiated with the object based on its inherent properties or technical possibilities. Rather than emerging through instrumental interaction with the objects, the fashion object prescribes in advance how it is to be dealt with. Once fashionable, the object synthesizes rituals on its own; it incorporates do's and don'ts, commandments and taboos; it prescribes ways to be carried, worn, spoken or dealt with, which overrule other ways of agency. Paradoxically, fashion turns the object into a Latourian 'mediator' by erasing or blurring its immediate practical or aesthetic properties and uses; it condones the object with a layer of appearance, thereby redefining its actions and reinserting it in other relations. However, this latter and more dynamic dimension to fashion cannot be wholly understood in a Durkheimian framework. Once more I should like to go back to Marx.

\section{The Fashion Object - The Inconspicuous Side}

In popular understanding, the term 'fashion' not only connotes shining objects, but also anonymous powers that control our object fascinations and identifications; a supra-individual circuit of things; a 'merry-go-round' or a 'system' in relation to which one should take a certain distance. As I 'expanded' Durkheim's thoughts above, I should have liked to expand Marx's and Baudrillard's ideas. However, it goes beyond the scope of this article to account for differences and similarities between Marx's conception of the circulation of commodities, the young Baudrillard's structuralist system of differences, and the nature of fashion dynamics. Let me simply point to the fact that the obscure sensation of hidden relations, of quasiautonomous dynamics - Wesenszusammenhänge - controlling phenomena, is central to the phenomenology of fashion. Fashion is, on the one hand, characterized by seemingly ordered processes of occurrence, recurrence and disappearance, at least in certain domains of its activities. On the other hand, it is also synonymous with sudden irruptions and absolute unpredictability. In short, fashion is not only emergent but also temporalized and dynamic. This is so because the objects and their respective cults are themselves subject to a supra-individual dynamic that constantly dissolves and instigates cults; constantly transforms our material and immaterial surroundings, illuminating certain objects and hollowing out others and thus eroding sentiments of authenticity and individuality. This dynamic 
surfaces in our language and our ideas and is to be found in all areas of our culture.

Normally, however, our attention is distracted from this hidden dynamic by new and shining fashion objects - this is my reformulation of the intuition of Debord and Haug. Another fashion object emerges, a shining and presumably sensual and particular object, which attracts our attention and thus obstructs the recognition of the autonomous and abstract dynamic characterizing fashion as such.

And yet this dynamic might suddenly become tangible. This happens when we are suddenly confronted with the unfashionable object. Fashion objects do not simply become old. They become unfashionable. They attain a peculiar cheap, gaudy or ridiculous appearance. Playing on Serres'opposition between 'blank' and 'black' quasi-objects, one might say that the fashion object is (mistakenly) appreciated as a black object, yet turns out to be disappointingly colourless. It was, after all, a 'joker', 'mere fashion. Or, in Latourian idiom: what seems to be a genuine 'mediator' was nothing but an 'intermediary' for deeper social forces. Danish author Karen Blixen (alias Isak Dinesen) relates her experience of coming back to Africa after a prolonged stay in Europe:

I have wondered why numb things placed aside in cupboards or on shelves, and in no way attacked by either moth or corrosion, in their unnoticed existence over the years suffer radical changes. I have seen it with my own dresses, bought in Europe but left in the wardrobe in Africa, when I after two or three years took them out to put them on, and they, without having stretched or shrunk, suddenly seemed to be too long or too short. They had not changed, and yet they were changed. Fashion and my own eyes caused this change. (1951: 10)

What Blixen experiences is the violent and sudden separation of sociality and materiality. The attraction of the object and the rituals it so convincingly prescribed was in no way inherent to it. It was all in the eyes of the beholders.

Abandoning a cult object is a distinctly modern occurrence, which finds no place in Durkheim's account. However, Blixen is not shocked just because she discovers that she belonged to a mimetic cult, but also because she perceives that she is subject to the play of fashion in itself, which is constantly changing and restructuring the inner social topography of the clan through objects. An autonomous dynamic exists, exerting its powers over actions and desires, which we do not normally observe, yet, "without knowing it', naturalize and maintain simply by following the shiny objects. Blixen not only discovers that identifications and fascinations, which she took to be her own, in fact are engendered by a cult, but that they are even subject to directions and orders surfacing from a dark hole behind the phenomena.

Like Latourian 'thinking machines', ozone layers or powerful gene technologies, fashion forces us to 'negotiate' on equal terms with the object world. 
Fashion forces us to comply with the autonomy of certain objects by granting them a whole new sphere of action. We (all) follow fashion. On the other hand it suddenly destroys this very autonomy altogether. It takes it all back again, reducing the object to cultic behaviour and anonymous autonomous forces.

In this perspective, fetishism is no ideological and totalitarian concept denying the potential 'actions' of objects in advance, but a real dynamic surfacing in the accounts of the informers and in the object world around us. One might say that Latour, because of his rather undiscriminating refusal of the concept of fetishism, effectively blocks himself from tracing the contours and the changes of the fashion object.

\section{Conclusion}

And yet Latour's basic intuition is correct: objects have largely been neglected by social theory. Thus, mediated through the inventive work of Latour, Serres' idea of the quasi-object plays a major role in the current 'objective turn' in sociology. I mean to have been true to the original inspiration from Serres even though in a rather unorthodox way. Thus, the main impetus of the present article was to contribute to this new movement in sociology, yet to insist on the fecundity of older theoretical and empirical insights, found in Marx and Durkheim, concerning fetishist social dynamics and fetishist phenomenology. In my view, the Durkheimian concept of exteriorization, and his conception of the relation between the sacred object and the cult, present a welcome opportunity for an important correction to one of the most common pitfalls of sociological fashion theory: the neglect of the shining object. My claim is that the member of the cult first and foremost sees this object. His love is real. In a word, it is only because the fashion object is no sign that it may function as a sign. The "communication theory of fashion' normally forgets this point completely; and so does the sociologist, who reduces cultural expression and preference to forms of 'exchange value' (Baudrillard) or value of 'distinction' (Bourdieu).

Moreover, this article insists on the broad concept of fashion. Consequently, in concluding, I should like to add the fashion object to Serres' list of institutionalized quasi-objects. Fashion would then be a 'social universal' (George Dumézil); an ordering or structuring principle functioning by way of a quasi-object; the fashion object would then be a kind of undetermined object, a 'pre-object', a 'joker', which receives its specific meaning when it is inserted into concrete social practice, i.e. turned into a definite object - in the same way as 'the military' creates order by betting on concrete weapons; and 'the economy' does so by circulating merchandises. The fashion object is the cult as well as the particular shining object: the appearance of the fashion object and its ability to assert itself, structuring the social, cannot be conceptualized separately. Thus I have taken seriously Durkheim's concept of 'exteriorization' and Marx's idea of 
'sensuous non-sensuous things' as phenomenological notions. Again, fetishism matters. This expression should be understood in all its equivocalness.

Just as with the other important quasi-objects, it is inherent to the workings of the fashion object that it is 'rare', limited in number. If everybody had it, it would not be subject to fashion dynamics. If everybody had huge amounts of money, it would have no worth - the same goes, evidently, for Serres' religious fetishes. The fashion object is neither a particular nor a universal, neither individual nor completely collective. If it was, it could not circulate and it could not 'asymmetrize' social relations.

In Serres' account, this dynamic is already, at least to a certain degree, incarnated in the phenomenology of the institutionalized quasi-object. This obviously goes for money and Serres' religious fetishes; but also for weapons, which, Serres asserted, only need to be shown or flashed in a social context to install a 'mute contract'. This phenomenological dimension, however, is of particular importance concerning fashion objects. They indeed appear to be rare; they shine or seem scarce and unique - when they are in fashion, that is. And yet they are not rare. Fashion might thrust itself on completely fortuitous objects. The shine of the object obscures its circulation, as it were; it blurs its abstract and general features and conveys to it a semblance of particularity and sensuousness. To a certain extent, this goes for all quasi-objects, but particularly for the fashion object. It radicalizes and sharpens the phenomenological dialectic between conspicuousness and inconspicuousness, between the concrete and the abstract, in a more extreme way than the others.

Now, it is one of the features of Serres' quasi-object theory that the different social universals adopt or absorb aspects from one another. In Serres, religion involves exchange and warfare, and science encompasses fetishist as well as economical aspects. Fashion, so I argued, has to a large extent replaced the traditional religious fetish, but it also interferes directly with the circulation of money, and it asserts itself in science and art. The spell of fashion befalls all objects which can be used to mark the individual, and its immediate attraction might outdo all kinds of empirical justification regimes connected with different cultural institutions. Thus the existence of the fashion object, and its ability to interfere with or even usurp other quasi-objects, might explain the existence of our two opposed phenomenologies in Serres' actual descriptions. Apparently, the fashion object appropriates or monopolizes as its own a phenomenological dialectic, aspects of which are found in all important quasi-objects.

It testifies to the continuous importance of these two phenomenologies that they can be found in a number of prominent accounts of modern object culture. And yet none of these accounts distinguishes sufficiently between the different mechanisms which cause the diverging appearances. In this article I have tried to redress some of this confusion. Due to their different origin, I have insisted on keeping the two fetishist phenomenologies apart analytically: a quasi-object might create an illuminated space around itself, constructing the social around itself like the planets circling 
around the sun, or, inversely, it might hollow out materiality and sociality like a black hole that itself remains unseen, yet absorbs all matter. It is neither money, nor weapons, nor the traditional religious fetish, which truly displays - unites and separates - these two phenomenologies. It is the fashion object.

\section{Notes}

1. Thus in the present article there can be no question of really (transcendentally) deducing the right or most suitable theory of fetishism from experience itself. I have deliberately made a theoretical choice and permitted myself to discard other possible candidates: especially the fetishist theories of Freudian or psychoanalytical origin, but also further reflections on fetishism in late Baudrillard.

2. Except for Serres (1982a), all translations into English are done by myself (BS).

3. See Latour (1996: 336ff.; 2007: 140ff.) and Hennion and Latour (1991). In my view, Latour is right in pointing out that one should be careful not to hypostasize tautological forces, variables or contexts explaining away concrete interaction and the 'actions' of objects. Nonetheless, the point of this article is that such forces do exist, and that they are, as we will see, tangible in the accounts delivered by the actors themselves and in the phenomenology of the objects. Only the notion of fetishism makes possible the description of the relation between cult and object in a quasi-object theoretical framework.

4. It is no coincidence that Luhmann takes up the notion of the quasi-object in his book on the art system, Die Kunst der Gesellschaft (1995: 8lff.). Thus, in a Habermasian perspective, quasi-objects - like 'system media' - would make communicative coordination of action obsolete. Moreover, it is clear that the very idea of the quasi-object casts doubt on Habermas's distinction between instrumental and solitary work on objects on the one hand, and social interaction and communication (without objects) on the other. For a Marxist praxis-philosophical perspective on this problematic, and yet one that is thoroughly interesting to quasi-object theory, see Márkus (1980: 71-83).

5. Frazer conceives of fetishism as an attempt to domesticate the surroundings by way of developing magical relations with certain objects. Like animism, this conception explains away religious experience as a phantasmagorical tendency on the part of the 'primitive mind' to cultivate dreams and illusions. It thus ignores that the remarkable phenomenology of the fetish results from real forces, i.e. social forces (Durkheim, 1998: 96-9, 248-67).

6. Just consider Marx's well-known remark that: 'the human senses, the humanity of the senses first comes into being with the existence of its objects. [...] The building of the five senses is a work of the whole world history up to now' (1971: 242).

7. Hartmut Böhme (2006: 345) sets the 'flop' rate of new products at around 80 percent.

8. Böhme is also aware of a fetishism of the system in late Marx (Böhme, 2006: 324ff.). Thus one wonders why Böhme, who even finds several different forms of fetishism at work in Marx, does not see the phenomenological opposition between speaking of, on the one hand, the 'fascinating force' [Faszinationsmacht] of the 
commodity, of its shine and its alluring powers (2006: 333); and, on the other hand, of the 'secret of the fetish' (2006: 322).

9. The quote is from Davis (1992: 151). Davis does not provide a reference for it.

References

Baudrillard, J. (2007) Pour une critique de l'économie politique du signe. Paris: Gallimard.

Blixen, K. (1951) Daguerreotypier. Copenhagen: Gylendal.

Böhme, H. (2006) Fetischismus und Kultur. Hamburg: Rowohlt Verlag GmbH.

Davis, F. (1992) Fashion, Culture and Identity. Chicago: University of Chicago Press.

Debord, G. (1992) La Société du spectacle. Paris: Gallimard.

Durkheim, E. (1998) Les Formes élémentaires de la vie religieuse. Paris: Quadrige/PUF.

Esposito, E. (2004) Die Verbindlichkeit des Vorübergehenden: Paradoxien der Mode. Frankfurt am Main: Suhrkamp Verlag.

Haug, F.W. (1976) Kritik der Warenästhetik. Frankfurt am Main: Suhrkamp Verlag.

Hennion, A. and B. Latour (1991) 'Objet d'art, objet de science. Note sur les limites de l'anti-fétichisme', Sociologie de l'art 4: 7-24.

Latour, B. (1996) 'On Interobjectivity', Mind, Culture, and Activity 3(4): 228-45.

Latour, B. (2007) Changer de société, refaire de la sociologie. Paris: La Découverte/Poche.

Luhmann, N. (1995) Die Kunst der Gesellschaft. Frankfurt am Main: Suhrkamp Verlag.

Márkus, G. (1980) 'Die Welt menschlicher Objekte. Zum Problem der Konstitution im Marxismus', in H. Axel and U. Jaeggi (eds) Arbeit, Normativität, Handlung: Theorien des historischen Materialismus, vol. 2. Frankfurt am Main: Suhrkamp Verlag.

Marx, K. (1964) Das Kapital, vol. III. Darmstat:Wissenschaftliche Buchgesellschaft. Marx, K. (1971) 'Die Deutsche Ideologie', in Die Frühschriften. Stuttgart: Alfred Kröner Verlag.

Marx, K. (1973) Das Kapital, vol. 1. Marx und Engels Werke. Berlin: Dietz Verlag. Ritzer, G. (2005) 'The Magical World of Consumption', Berkeley Journal of Sociology: 118-37.

Serres, M. (1982a) The Parasite. Baltimore, MD: Johns Hopkins University Press. Serres, M. (1982b) Genèse. Paris: Bernard Grasset.

Serres, M. (with Bruno Latour) (1995) Conversations on Science, Culture, and Time. Ann Arbor: University of Michigan Press.

Bjørn Schiermer is Assistant Professor at the Department of Sociology, University of Copenhagen. His main research field is sociological theory and the sociology of fashion. [email: bsa@sociology.ku.dk] 